"Banking and income inequality of the American community: an analysis"

\begin{tabular}{ll} 
AUTHORS & $\begin{array}{l}\text { Lijing Du } \\
\text { Michail Dewally } \\
\text { Ying Ying Shao } \\
\text { Daniel Singer }\end{array}$ \\
\hline Lijing Du, Michail Dewally, Ying Ying Shao and Daniel Singer (2016). Banking \\
and income inequality of the American community: an analysis. Banks and Bank \\
Systems, 11(1), 52-59. doi:10.21511/bbs.11(1).2016.06
\end{tabular}

NUMBER OF REFERENCES

0

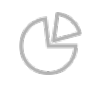

NUMBER OF FIGURES

0

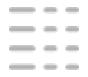

NUMBER OF TABLES

0

(C) The author(s) 2022. This publication is an open access article. 
Lijing Du (USA), Michail Dewally (USA), Ying Ying Shao (USA), Daniel Singer (USA)

\title{
Banking and income inequality of the American community: an analysis
}

\begin{abstract}
Community banks in American urban areas are found to have a significant effect on the local distribution of income. Banking activity is seen to both decrease inequality by increasing the median level of income and simultaneously increase inequality by increasing the size of either tail of the income distribution. The net effect of banks providing liquidity to the American local economy and increasing access to the banking infrastructure is to decrease income inequality in these communities.
\end{abstract}

Keywords: financial markets, financial institutions, income distribution, public policy. JEL Classification: G2, E5, R2.

\section{Introduction}

This paper examines the impact of community banking activities on the complex relationships between income levels and its distribution in urban American counties. The contribution of this paper lies in specifying the linkages between banking activity and income creation and how those linkages impact the local distribution of income.

Recent concerns about the current growth in income inequality have resulted in politicians and social leaders calling for a reduction in income inequality, but this concern has been largely rhetorical. It is felt that growing inequality in the American economy reflects an increasing reliance on financial markets to accomplish economic objectives. This trend towards market driven incentives to promote innovation and entrepreneurship necessarily results in a less equal distribution of income (Piketty and Saez, 2003). The impact of banking activity on the distribution of income may be particularly strong in developing nations (Ali and Medhekar, 2013).

\section{Banking and inequality}

Research on the impact of banks on the distribution of income has been mixed. Piketty (2013) has found that over the long-term the return on capital in developed countries is greater than the rate of economic growth resulting in an increase in income inequality. Stiglitz (2015) similarly argues that a positive relationship between growth and inequality results from monopoly rents on finite resources. In contrast, Shuai (2015) finds a negative relationship between income growth and inequality. Other researchers can find no consistent relationship between inequality and growth (Lundberg and Squire,

(c) Lijing Du, Michail Dewally, Ying Ying Shao, Daniel Singer, 2016. Lijing Du, Dr., Assistant Professor of Finance, Towson University, USA.

Michail Dewally, Dr., Assistant Professor of Finance, Towson University, USA.

Ying Ying Shao, Dr., Assistant Professor of Finance, Towson University, USA.

Daniel Singer, Dr., Professor of Finance, Towson University, USA.
2003). A considerable body of research has been unable to confirm a positive relationship between economic growth and equality as a result of the complexity of the issues involved (Dollar et al., 2015).

1.2. The face of inequality. The most commonly used measure of income inequality is the Gini ratio (the ratio of the difference between the actual cumulative distribution of income (the Lorenz curve) and the cumulative distribution of income if all income was equally distributed). A Gini ratio of zero expresses perfect equality and a Gini ratio of one represents the maximum possible inequality.

In a list of 141 countries, the Gini ratio ranged from .632 in Lesotho to .230 in Sweden with the United States 41st in the distribution (CIA, 2014). The Current Population Survey puts the Gini ratio in the United States for 2013 at .476, up from .454 in 1993, the earliest comparable year (DeNavas-Walt and Proctor, 2013). In 807 counties covered in 2013 U.S. Census American Community Survey in 2013 the average Gini ratio for counties was .449 with a standard deviation of .036.

\section{Literature}

2.1. Socio-economic determinants of economic growth and inequality. The subject of the relationship between the financial system and the distribution of income has received much study, but numerous issues remain ambiguous. A particular difficulty in regional analysis are spillover effects arising from endogeneity among the different variables (LeSage, 2014). We understand that the location of a bank and its footprints are distinct and we are careful in the creation of our liquidity variables to account for the liquidity created in adjoining counties so as to account to an extent the spillover effects that liquidity created in the next county impacts the income level in our county of interest.

The relationship between economic growth and the distribution of income is dependent on a host of sociological and economic factors. Fortunately, 
much work in this area has already been accomplished (Zhang and Hu, 2011). Following this tradition, a framework for determining income creation is postulated in this study as:

$M D H Y_{i}=\alpha+\beta \% M H_{i}+\gamma \% E d<9 i+\delta \% B A C H_{i}+$ $+\theta \% F L F P_{i}+\rho \% M L F P+\varepsilon$,

where $M D H Y=$ Median Household Income, \% MH $=\%$ of Married Household, $\% E d<9=\%$ of population with less than 9 years of education, $\% B A C H$ $=\%$ of population with Bachelor degree, $\%$ FLFP $=$ $\%$ of female labor force participation, $\% M L F P=\%$ of male labor force participation.

2.1.1. Family formation. Family formation, particularly within the covenant of marriage, has a welldocumented effect on lifetime earnings and wealth (Zissimopoulos et al., 2015). This effect is generally found to reflect the advantages of the division of labor within the household and advantages in creating human capital both of which result in higher productivity and increased earnings.

2.1.2. Education. Research on the interdependence of education and income has a venerable history (Sauer and Zagler, 2012). Zeira (2009) found a positive relationship between economic growth and education based on the fact that economic growth requires technological change, and technological change is driven by an educated workforce. Recent research has suggested that limitations on the supply of highly educated workers lead to changes in the wage structure that contribute to inequality (Huber and Stephens, 2014).

2.1.3. Labor force participation. This study uses the labor force participation of males and females as separate factors in determining household income. Labor force participation is an elastic concept because when labor market conditions improve, individuals who were out of the labor force because they were not actively seeking employment move into the labor force because of better perceived opportunities for employment (the additional worker effect). Conversely, there is a discouraged worker effect of workers of individuals ceasing to seek employment in the face of deteriorating labor market conditions (Dagsvik et al., 2013).

LFP is higher for individuals living in families than for individuals living in single or multiple person households. Marriage, fertility decisions and the presence of young children in the family are also seen to influence LFP decisions (Kondo, 2011). Social mores concerning LFP tend to develop over time and become entrenched in regional behaviors.

\section{The banking sector and income growth}

In addition to the traditional formulation of income determinants presented in Equation 1, we wish to take account of the impact of the banking sector on economic growth. Banking activities are critical to creating economic growth (Ali, 2003). Economic growth requires the creation and deployment of capital to finance economic activity. Community banks may be expected to play an important role in this process. They may have greater insight into local market conditions and knowledge of the strengths and weaknesses of small businessmen and entrepreneurs in that area that regional or national banks might not have (Leyshon et al., 2006).

Community banks have the opportunity to finance job-creating economic activities that would not, otherwise, occur, thus, increasing income levels in the locality. The requisite knowledge to undertake such capital deployment would be facilitated by a close relationship between the bank and individuals in the community. Consequently, creating liquidity and providing access to banking facilities may be considered to be a social responsibility of the banking system (Wise and Ali, 2008).

Banks play a critical role in the creation and deployment of capital through the process of liquefying financial assets and liabilities. They facilitate this process by financing illiquid assets with liquid liabilities and thereby transforming risky loans into relatively riskless deposits (DeAngelo and Stulz, 2015). The impact of liquidity creation on economic growth and the distribution of income has not been thoroughly studied due to difficulties in measuring bank liquidity. Berger and Bouwman (2009) have recently studied the process of liquidity creation and developed a workable measure of liquidity which is used in this study.

\section{Methodology}

This study uses survey data developed by the Bureau of the Census, American Community Survey for 2013. The American Community Survey samples about 3.5 million households every year to supplement the Census Bureau's decennial census program. The Survey includes a wide range of selfreported social, economic and housing data. While the one year tabulation for 2013 covers 817 separate counties, this study utilizes the data from the 437 urban counties for which the relevant data are available in the 2013 survey.

4.1. Gini ratios. A difficulty in using the Gini ratio to examine income inequality is the fact that the same Gini ratio can reflect two entirely different distributions of income (Hagerbaumer, 1977). While a given change in the level of income may leave the shape of the Lorenz curve unaffected, a more likely occurrence is that the slope of the Lorenz curve will change depending on whether the impact of a change in modality income levels is felt on the lower or upper end of the distribution (Ceria- 
ni and Verme, 2015). This problem may be addressed by examining the causes of changing income levels. An additional difficulty is that the larger and more heterogeneous the unit of observation, the less likely the Gini is to reflect the actual inequality in the distribution of income because of offsetting variations among population subgroups (Frosini, 2012).

4.2. Banking activity. The impact of banking activity on economic growth and the distribution of income arises from (1) the extent to which banks provide access to the banking infrastructure and (2) the extent to which their liquidity creation activities foster economic growth (Ali, 2003). This paper uses a measure of liquidity creation developed by Berger and Bouwman (2009) to assess the impact of the banking system on the relationship between the distribution of income and economic growth. It uses their preferred measure of liquidity creation ("cat fat") to investigate the impact of community bank activity on the distribution of income in counties covered by the ACS.

4.2.1. Access to the banking infrastructure. A healthy local economy provides access for individuals to the local banking system. Participation in the banking system tends to create feedback linkages supporting economic growth. Fully banked individuals maintain checking and savings accounts and borrow from local banks to finance their homes and purchase consumer durables. The quality and quantity of contact with local entrepreneurs and small businessmen creates important knowledge that al lows the local banks to fund the fixed and working capital needs of individuals and local businesses in the community. Unbanked individuals have no formal relationships with their community banks and, thus, are isolated to that extent from active participation in the economic life of their community.

\subsubsection{Liquidity creation. Banks have traditionally} been seen as "risk transformers", shifting riskless deposits to finance risky loans. While this process usually creates liquidity, these two functions do not necessarily move in tandem. Research on the interaction of these functions has been limited by the difficulty in measuring liquidity creation until the ground-breaking work of Berger and Bouwman (2009). Their approach yielded four different measures of liquidity: "cat fat", "mat fat", "cat nonfat", and "mat nonfat". Berger and Bouwman (2009, p. 3797) prefer "cat fat" as the most appropriate way to measure liquidity because the type of asset has a greater impact on its liquidity than its maturation date and because off-balance sheet and onbalance sheet items are functionally similar.

\section{Findings}

5.1. Modal income levels. Understanding the implications of a rise in general income levels for income inequality, thus, requires considering the determinants of the general level of income. Equation 1 in Table 1 specifies the general model of income determination presented in Equation 1. Together, the four significant variables presented in Equation 1 explain $63 \%$ of the variation in Median Household Income across the surveyed ACS counties.

Table 1. Influences on median family income

\begin{tabular}{|c|c|c|c|c|}
\hline $\begin{array}{l}\text { Dependent variable: median } \\
\text { household income }\end{array}$ & (1) & (2) & (3) & (4) \\
\hline \multirow{2}{*}{$\% \mathrm{MH}$} & $0.484^{* *}$ & & & $936.16^{\star \star}$ \\
\hline & $(16.475)$ & & & $(17.800)$ \\
\hline \multirow{2}{*}{$\% \mathrm{ED}<9$} & $-0.086^{* *}$ & & & $358.39^{\star \star}$ \\
\hline & $(-2.821)$ & & & $(2.760)$ \\
\hline \multirow{2}{*}{$\% \mathrm{BACH}$} & $0.526^{\star \star}$ & & & $1,259.49$ \\
\hline & $(14.380)$ & & & (14.710) \\
\hline \multirow{2}{*}{$\%$ FLFP } & $0.218^{* *}$ & & & $571.94^{* *}$ \\
\hline & $(4.945)$ & & & $(6.540)$ \\
\hline \multirow{2}{*}{$\%$ MLFP } & $0.009^{\star \star}$ & & & \\
\hline & $(0.206)$ & & & \\
\hline \multirow{2}{*}{$\% \mathrm{NB}$} & & $-0.260^{*}$ & $0.338^{\star \star}$ & \\
\hline & & $(-2.280)$ & $(7.735)$ & \\
\hline \multirow{2}{*}{$\% \mathrm{FB}$} & & -0.025 & $-0.258^{* *}$ & \\
\hline & & $(-0.220)$ & $(-5.915)$ & \\
\hline \multirow{2}{*}{$\%$ CF $/ \mathrm{TA}$} & - & $\begin{array}{l}-0.057 \\
\end{array}$ & - & -23.95 \\
\hline & - & $(-0.903)$ & - & $(-0.820)$ \\
\hline \multirow{2}{*}{$\mathrm{CF}$} & - & $0.178^{\star \star}$ & - & 0.0008 \\
\hline & - & (2.834) & - & $(1.07)$ \\
\hline \multirow{2}{*}{ Constant } & 0.481 & 68.660 & 59.796 & -42.246 \\
\hline & & & & \\
\hline
\end{tabular}


Table 1 (cont.). Influences on median family income

\begin{tabular}{|l|c|c|c|c|}
\hline $\begin{array}{c}\text { Dependent variable: median } \\
\text { household income }\end{array}$ & (1) & (2) & (3) & (4) \\
\hline \multirow{2}{*}{ R-squared } & 0.630 & 0.073 & 0.174 & 0.687 \\
\cline { 2 - 5 } & & & & \\
\hline
\end{tabular}

Note: The dependent variable is the annual median household income. The independent variables in percentage are percentages of, respectively, MH (married household), ED < 9 (population with less than 9 years of education), BACH (population with a Bachelor degree), FLFP (female labor force participation), MLFP (male labor force participation), NB (population not banked), FB (population fully banked), CF/TA (cat fat as a $\%$ of total assets). CF is the absolute amount of cat fat created in the local economy. $t$ values are reported in the parentheses. ${ }^{* *}, *$ denote significance at the $1 \%$ and $5 \%$ levels, respectively.

The positive and significant coefficient for marriage in Table 1, Equation 1 confirms the findings of the literature on family formation above. The negative coefficient between median family income and those with less than 9 years of formal education, and the positive coefficient between median family income and those with a Bachelor degree in this study are also consistent with prior research on the relationship between education and income.

5.2. Banking and income creation. The impact of the banking sector on median income is hypothesized to occur by (1) providing access to individuals to banking functions to allow them to fully participate in the local economy and (2) by creating liquid assets and liabilities that encourage the creation of capital in the local community and provides for risk shifting and risk pooling that encourages capital spending. The direct impact of these factors on median income is presented in Table 1, Equation 2.

5.2.1. Banking access and income growth. A comparison of regressions 2 and 3 in Table 1 is suggestive of a strong interrelationship between liquidity creation and the extent of local banks relationships within the community. A negative relationship between those fully banked and median income and a positive relationship between the unbanked and median income in regression 3 would seem perverse. However, this relationship changes its sign (in the case of those unbanked) or becomes insignificant (in the case of the fully banked). This lack of consistency may reflect the complexity of the interrelationship between banking, income and the other determinants of income. A significant positive coefficient between the level of median income and fully banked individuals is not found, possibly, because this factor is overwhelmed by the other determinants of median income.

It is certainly possible that in areas with lower incomes, individuals are less likely to enter into banking relationships. However, even in low income areas, there will be more individuals who are underbanked, rather than having no relationship at all with a bank. An environment which reduces the number of unbanked individuals draws more capital into the hands of financial intermediaries and fos- ters economic growth. Regression 2 in Table 1 may reflect the fact that the absence of an independent variable for liquidity creation removes the positive impact of liquidity creation on income which obscures the positive impact of the fully banked on income.

5.2.2. Liquidity creation and income growth. Another important impact banks have on the level of income in the community is through the creation of liquidity which provides capital to maintain and grow the level of economic activity. Liquidity creation in the local economy has both demand side and supply side attributes. The demand side is characterized by the demand for liquid assets such as demand deposits and lines of credit by both business and consumers. Supply is created when banks finance illiquid assets such as mortgages and longterm commercial and industrial loans. Liquidity is created through the banks transforming the risky illiquid assets into almost riskless liquid assets (Horvath et al., 2016).

The effect of making both banking assets and liabilities more liquid facilitates both consumption and investment spending, both of which can have a positive impact on income levels. Where the access to money and capital is easier, less costly and more timely economic processes are encouraged.

The coefficients presented in Equation 2 in Table 1 show the positive impact of liquidity creation ("catfat") on the level of median income, confirming earlier thought about the positive impact of liquidity creation on income levels. Equation 2 in Table 1 measures the relative extent of liquidity creating (CF/TA) by local banks refers to an issue discussed by financial theorists under the headings of the alternative "financial-fragility-crowding out" and "risk absorption" hypotheses (Berger and Bouwman, 2009). Whatever the cause of this banking behavior, a lower ratio would suggest less aggressiveness in creating liquidity, a higher ratio more liquidity more aggressiveness. The absence of a significant coefficient for this variable suggests that it is not the strategic posture of banks that impacts local economic activity, but the actual amount of liquidity created ("cat fat"). 


\subsection{The tails of the income distribution. Table 2} reveals that when median household income is held constant, the two tails of the distribution are positively, but not perfectly correlated. This implies that there are factors in the income creation process that can impact inequality independent of their impact on median income. Specifically, this means that when median income increases reducing overall inequality, simultaneous economic forces operate at either end of the distribution to increase inequality. The significant positive coefficient of median income in Table 2 between the two tails of the distribution indicates that while some socio-economic forces may impact both tails, others may affect one tail but not the other. The specific impact of any change will depend on the idiosyncratic characteristics of that particular economic force. However, overall, it is clear that changes in the modal level of income will outweigh any impact on the tails of the distribution.

Table 2. Income distribution partial correlations

\begin{tabular}{|l|c|c|c|}
\hline & Gini & $\mathrm{HY}<10 \mathrm{k}$ & $\mathrm{HY}>200 \mathrm{k}$ \\
\hline Gini & 1 & $0.625^{* *}$ & $0.863^{\star *}$ \\
\hline $\mathrm{HY}<10 \mathrm{k}$ & & 1 & $0.534^{\star *}$ \\
\hline $\mathrm{HY}>200 \mathrm{k}$ & & 1 \\
\hline${ }^{*}$ Controlling for MDHY \\
\hline${ }^{* \star} \mathrm{P}=.01$ \\
\hline $\mathrm{HY}<10 \mathrm{k}=\%$ of households $<\$ 10.000$ \\
\hline$H Y>200 \mathrm{k}=\%$ of households $>\$ 200.000$ \\
\hline
\end{tabular}

5.3.1. Reconciling the impact of banking on inequality. While the socio-economic variables enter as expected in Table 1, Equation 4, the variables reflecting banking activities do not. The lack of significance for both "cat fat" and the incidence of those fully banked in influencing median income levels may be explained by either the absolute dominance of socio-economic variables in impacting median levels of income or an endogenous relationship between the banking and socio-economic variables (e.g., less educated individuals are more likely to be not banked).

5.4. Factors impacting income inequality. The simple regression of median household income on the Gini coefficient presented in Table 3, Equation 1 below suggests that while the impact of income levels on income inequality is significantly negative (higher income levels reduce inequality), the effect is small. This result conceals the impact of income creation on the tails of the Lorenz curve. From the partial correlations presented in Table 2 it can be seen that both tails are significantly and positively related to income inequality. Thus, the overall negative effect of an increase in income on income inequality conceals shifts in the distribution of income that may have important social consequences.

Table 3 also reports the results of more comprehensive regressions examining the relationship of the socioeconomic variables discussed above variables with the Gini coefficient. Equation 2 in Table 3 synthesizes the impact of this process on income inequality in terms of the eight socio-economic and banking variables discussed above that explain more than three-quarters of the variance in inequality among the ACS counties included in this survey.

The relative presence of individuals with Bachelor degree is seen to, primarily, impact the upper end of the income distribution, resulting in greater income inequality in the local area. The absence of a significant positive coefficient with Gini for the relative number of individuals with less than 9 years of education resulting is unexpected and suggests that the structure of educational attainment in a given area has the most powerful effect at the higher end of the income distribution. Female labor force participation is seen to impact the upper end of the income distribution more than the lower end of the distribution, consistent with the latest findings in this area.

Table 3. Influences on income inequality

\begin{tabular}{|c|c|c|c|}
\hline $\begin{array}{l}\text { Dependent variable: } \\
\text { Gini coefficient }\end{array}$ & (1) & (2) & (3) \\
\hline \multirow{2}{*}{ MDHY } & $-0.207^{\star \star}$ & $-1.262^{\star *}$ & - \\
\hline & $(-4.423)$ & $(-18.944)$ & - \\
\hline \multirow{2}{*}{$\% \mathrm{HY}<10 \mathrm{k}$} & - & $0.319^{* *}$ & - \\
\hline & - & $(8.838)$ & - \\
\hline \multirow{2}{*}{$\% H Y>200 k$} & - & $1.308^{\star \star}$ & - \\
\hline & - & $(25.067)$ & - \\
\hline \multirow{2}{*}{$\%$ FLFP } & - & $0.050^{\star *}$ & - \\
\hline & - & $(2.952)$ & - \\
\hline \multirow[t]{2}{*}{$\mathrm{CF}$} & - & 0.044 & $\begin{array}{c}0.476^{* *} \\
(11 .\end{array}$ \\
\hline & - & $(0.884)$ & (11.222) \\
\hline \multirow{2}{*}{$\% \mathrm{FB}$} & - & 0.016 & $0.114^{\star *}$ \\
\hline & - & $(0.430)$ & $(2.681)$ \\
\hline \multirow{2}{*}{$\% \mathrm{ED}<9$} & - & 0.034 & - \\
\hline & - & $(0.941)$ & - \\
\hline
\end{tabular}


Table 3 (cont.). Influences on income inequality

\begin{tabular}{|l|c|c|c|}
\hline Dependent variable: Gini coefficient & $(1)$ & $(2)$ & $(3)$ \\
\hline \multirow{2}{*}{$\% \mathrm{BACH}$} & - & $0.200^{\star *}$ & - \\
\cline { 2 - 4 } & - & $(5.262)$ & - \\
\hline Constant & 0.481 & 0.522 & 0.230 \\
\hline R-squared & 0.043 & 0.815 & 0.116 \\
\hline
\end{tabular}

Note: The dependent variable is the Gini coefficient. The independent variables in percentage are percentages of, respectively, HY < 10k (households $<\$ 10,000$ income), HY > 200k (households > \$200,000 income), FLFP (female labor force participation), FB (population fully banked), ED $<9$ (population with less than 9 years of education), BACH (population with a Bachelor degree). $\mathrm{CF}$ is the absolute amount of "cat fat" created in the local economy. $t$-values are reported in the parentheses. $* * *$ denote significance at the $1 \%$ and $5 \%$ levels, respectively.

Neither the liquidity creation activities of banks nor the presence of fully banked individuals are seen in Equation 2, Table 3 to have a significant impact on income inequality. However, the lack of significance of liquidity and the incidence of fully banked individual may be concealed by the large negative impact of median household income on inequality.

5.4.1. The direct impact of local bank activities on income inequality. Equation 3 in Table 3 shows the positive and significant impact of both "cat fat" creation and the incidence of the fully banked on income inequality. While increases in either of these variables could increase income inequality by decreasing income in the lower portion of the Lorenz curve or increasing it in the upper portion of the curve, it is more likely that the impact will be felt on the upper reaches of the Lorenz curve because both factors will increase the level of income through expanding opportunities for the more affluent component of the population.

5.4.2. The indirect impact of bank activity on income inequality. Exactly why Equation 3 in Table 3 shows that increases in liquidity or banking participation are associated with greater income inequality and can be investigated by regressing these variables on the tails of the distribution as is done in Table 4. The positive impact on inequality as measured by the Gini is seen to result from the impact of both liquidity creation and bank participation increases on the lower tail of the distribution as evidenced by the positive coefficient for the percentage of households with less than $\$ 10,000$ of income and the absence of this effect for households with over $\$ 200,000$ of income. A significant impact from both liquidity creation and bank participation on the upper tail of the distribution is noticeably lacking.
Table 4. Income inequality and the tails of the distribution

\begin{tabular}{|l|c|c|}
\hline Dependent variables & $\begin{array}{c}(1) \\
\% \mathrm{HY}<10 \mathrm{k}\end{array}$ & $\begin{array}{c}(2) \\
\% \mathrm{HY}>200 \mathrm{k}\end{array}$ \\
\hline \multirow{2}{*}{$\mathrm{CF}$} & $0.476^{\star *}$ & 0.212 \\
\cline { 2 - 3 } & $(11.222)$ & $(0.987)$ \\
\hline \multirow{2}{*}{$\% \mathrm{FB}$} & $0.114^{* *}$ & -0.065 \\
\hline Constant & $(2.681)$ & $(-0.031)$ \\
\hline R-squared & 0.230 & 0.089 \\
\hline
\end{tabular}

This Table reports the results of regressions examining the effect of banking and liquidity creation on income level. The dependent variables HY < 10k and HY > 200k, respectively, are the proportion of the population with annual income under $\$ 10,000$ and over $\$ 200,000$. The independent variables are $\mathrm{CF}$ is the absolute amount of "cat fat" created in the local economy and $\% \mathrm{FB}$, the proportion of the population fully banked. $t$ values are reported in the parentheses. **, * denote significance at the $1 \%$ and $5 \%$ levels, respectively.

The result of this test is that "cat fat" and the percent of fully banked individuals contribute to income inequality, primarily, through their impact at the lower end of the Lorenz curve. It may be concluded from the above analysis that the impact of liquidity creation and the incidence of banking use in a community simultaneously impact both the modal level of income as well as the tails of the distribution, with the net effect of an increase in either of these variables decreases income inequality.

An alternative approach to testing the hypothesis that the banking variables impact both modal levels of income (decreasing inequality) and the tails of the distribution (increasing inequality) would be provided by examining the partial correlations of the indicated variables, holding median income constant. These are presented in Table 5.

Table 5. Inequality partial correlations

\begin{tabular}{|l|c|c|c|c|c|c|}
\hline & $\mathrm{GINI}$ & $\mathrm{HY}<10$ & $\mathrm{HY}>200 \mathrm{k}$ & $\% \mathrm{FB}$ & $\% \mathrm{NB}$ & $\mathrm{CF}$ \\
\hline $\mathrm{GINI}$ & 1 & $.625^{\star \star}$ & $.863^{\star \star}$ & $.438^{\star \star}$ & $.132^{\star}$ & $.200^{\star \star}$ \\
\hline $\mathrm{HY}<10 \mathrm{k}$ & & 1 & $.534^{\star \star}$ & $.306^{\star \star}$ & $.207^{\star \star}$ & .024 \\
\hline $\mathrm{HY}>200 \mathrm{k}$ & & & 1 & $.461^{\star \star}$ & $.213^{\star \star}$ & $.171^{\star \star}$ \\
\hline$\% \mathrm{FB}$ & & & & 1 & $.132^{\star \star}$ & $.141^{\star \star}$ \\
\hline
\end{tabular}


Table 5 (cont.). Inequality partial correlations

\begin{tabular}{|l|l|l|l|l|l|c|}
\hline & $\mathrm{GINI}$ & $\mathrm{HY}<10$ & $\mathrm{HY}>200 \mathrm{k}$ & $\% \mathrm{FB}$ & $\% \mathrm{NB}$ & $\mathrm{CF}$ \\
\hline$\% \mathrm{NB}$ & & & & & 1 & .008 \\
\hline $\mathrm{CF}$ & & & & & & 1 \\
\hline
\end{tabular}

Note: Controlling for Median Household Income. Gini is the Gini coefficient, HY < 10k are households with income under $\$ 10,000$, HY > 100k are households with income over $\$ 200,000, \%$ FB is the percent of the population fully banked, $\%$ NB is the percent of the population not banked, $\mathrm{CF}$ is "cat fat", our measure of liquidity creation. $* * \mathrm{p}=.01, * \mathrm{p}=.01$.

Table 5 reveals the importance of the tails of the income distribution in determining income inequality. The positive, but less than perfect, correlation between the two tails of the distribution in Table 5 indicates that the factors impacting inequality can operate independently at either end of the distribution. "Cat fat" and the incidence of those fully banked are seen significantly and positively related to income inequality. A connection is also found between liquidity creation and the incidence of those fully banked, suggesting the coming led impact of banks on their communities.

5.5. Variations in the trend between the impact of banking on the distribution of income in developed and developing countries. Can the findings of a positive impact on the banking system in a developed country such as the USA be generalized to a developing nation such as Bangladesh? Sarkar et al. (2015) found a strong positive relationship between the banking sectors' financing in agriculture and agriculture output in Bangladesh and that banking credits also facilitate financial inclusion in Bangladesh. The current trend to the increasing deregulation of the banking sector in Bangladesh suggests increasing competition among banks that is creating behavior similar to that characterizing banks in developing countries (Uddin et al., 2015). However, increasing competition and other dynamic changes in the banking sector may mitigate against a positive relationship between banking activity and decreasing income inequality (Ali, 2003). This is, clearly, an area requiring further investigation.

\section{Conclusions}

Research findings. The findings of this paper provide evidence that the banking functions of creating liquidity and increasing access to the financial infrastructure have two effects: (1) increasing the general level of income (increasing income equality), and (2) decreasing the slope of the lower portion of the Lo- renz curve and increasing the slope of the upper portion of the Lorenz Curve (increasing income inequality). The net effect of community banks creating liquidity and access to the financial infrastructure is found to decrease inequality in the distribution of income.

Limitations of the study. In America, the distribution of income reflects not only market activities, but also the operation of a host of non-market factors. Chief among these are governmental taxing and subsidy policies. The impact of these policies on the actual distribution of income may overwhelm the impact of market forces on this distribution.

The excessive reliance on financial markets in America may be generating a dynamic force which, over time, will increase the adverse impact of banking on income inequality. It is difficult to capture such an effect in cross-sectional analysis. To the extent government policies do not support market outcomes characterized by greater equality, achieving a more equal distribution of income may remain an elusive goal.

Recommendations for further research. The topic of the impact of the banking sector on the distribution of income is an important one. Insofar, as governmental policy fosters an approach to economic growth which relies on the banking system to provide capital and equal access to individuals, the longrun impact of such policies will be controversial.

Addressing such controversial issues successfully will be more effective if research can provide information on exactly how the liquidity creation process works (especially in developing countries) and can identify the specific linkages between job creation and economic output and the activities of the banking sector. Access to the banking sector per se may not influence economic activity by itself. There are, no doubt, other factors in this process which must be considered.

\section{References}

1. Ali, Muhammed Mahboob. (2003). Impact of Globalization Process on Corporate Planning of Commercial Banks in Bangladesh: A Survey of Banker's Opinion, Journal of Economic Cooperation Among Islamic Countries, 24 (3).

2. Medhekar, Anita. (2013) Role of Financial Intermediaries in Creating International Financial Shock with Special Reference to Bangladesh: a critical review, Journal of Banks and Banks System, 6 (1). 
3. Berger, Allen N. and Bouwman, Christa, H.S. (2009). Bank Liquidity Creation, Review of Financial Studies, 22 , pp. 3779-3837.

4. Ceriani, Lidia and Verme, Paolo. (2015). Individual Diversity and the Gini Decomposition, Social Indicators Research, 121, pp. 637-646.

5. CIA (2014). The World Factbook. Accessed: December 30, 2014. Available at: https://www.cia.gov/library/ publications/the-world-factbook/rankorder/2172.

6. Dagsvik, John, Kornstad, Tom and Skjerpen, Terje. (2013). Labor force participation and the discouraged worker effect, Empirical Economics, 45 (1), pp. 401-433.

7. DeAngelo, H. and Stulz, R. (2015). Liquid-claim production, risk management, and bank capital structure: why high leverage is optimal for banks, Journal of Financial Economics, 116, pp. 219-236.

8. DeNavas-Walt, C. and Proctor, B.D. (2013). Census Bureau, Income and Poverty in the United States, Current Population Reports, U.S. Government Printing Office, Washington, DC, pp. 60-249.

9. Dollar, David, Kleineberg, T. and Kraay, Art. (2015). Growth, inequality and social welfare: Frosini, Benito (2012) Approximation and decomposition of Gini, Pietra-Ricci and Theil inequality measures, Empirical Economics, 43, pp. 175-197.

10. Hagerbaumer, James B. (1977). The Gini concentration ratio and the minor concentration ratio: A two parameter index of inequality, Review of Economics \& Statistics, 59, pp. 377-381.

11. Horvath, Roman, Seidler, Jakub and Weill, Laurent. (2016). How bank competition influences liquidity creation, Economic Modelling, 52 (A), pp. 155-161.

12. Huber, Evelyne and Stephens, John D. (2014). Income inequality and redistribution in post-industrial democracies: demographic, economic and political determinants, Socio-Economic Review, 12, pp. 245-267.

13. Kondo, Ayako. (2011). Gender-specific labor market conditions and family formation, Journal of Population Economics, 25, pp. 151-174.

14. LeSage, James P. (2014). What regional scientists need to know about spatial econometrics, The Review of Regional Studies, 44 (1), pp. 13-32.

15. Leyshon, A., Signoretta, P., Knights, D., Alferoff, C. and Burton, D. (2006). Walking with moneylenders: The ecology of the UK home-collected credit industry, Urban Studies (Routledge), 43 (1), pp. 161-186.

16. Lundberg, Mattias and Squire, L. (2003). The simultaneous evolution of growth and inequality, Economic Journal, 113 , p. 326-344.

17. Piketty, T. (2013). Capital in the Twenty-First Century. Cambridge, MA: Belknap Press.

18. Piketty, T. and Saez, E. (2003). Income Inequality in the United States, 1913-1998, The Quarterly Journal of Economics, 118, pp. 1-39.

19. Sauer, Petra and Zagler, M. (2012). Economic Growth and the Quantity and Distribution of Education: A Survey, Journal of Economic Surveys, 26, pp. 933-951.

20. Shuai, Xiaobing. (2015). Do Economic Development Efforts Benefit All? Business Attraction and Income Inequality, The Review of Regional Studies, 45 (1), pp. 35-56.

21. Stiglitz, Joseph E. (2015). The origins of Inequality and Policies to contain it, National Tax Journal, Jun 2015, 68 (2), pp. 425-448.

22. Uddin, S.M. and Sohrab, Yasushi Suzuki. (2015). The Dynamics of Concentration and Competition in the Banking Sector of Bangladesh: An Empirical Investigation, South Asian Journal of Management, 22 (1), pp. 114-136.

23. Wise, Victoria and Ali, Muhammed Mahboob. (2008). Case Studies on Corporate Governance and Corporate Social Responsibility, South Asian Journal of Management, 15 (3).

24. Zeira, Joseph. (2009). Why and How Education Affects Economic Growth, Review of International Economics, 17, pp. 602-614.

25. Zhang, Peng and Xu, Mann. (2011). The View from the County: China's Regional Inequalities of Socio-Economic Development, Annals of Economics and Science, 12 (1), pp. 183-198. 